Such facts, while not explicable on the ground that the inhibition is due merely to a trace of alkali derived from the glass, form a confirmation of the theoretical considerations put forward in our paper.

July 7 .

W. Cramer.

\section{Origin of a Mathematical Symbol for Variation.}

As a contribution to the history of algebraic notation it may be worth while to point out that the symbol $\propto$ for variation was introduced by William Emerson. In his "Doctrine of Fluxions," third edition, London, I 768 (first edition, I749), he says on p. $4:-$ "To the common Algebraic Characters already receiv'd I add this $\propto$, which signifies a general Proportion; thus, $A \propto \frac{B C}{D}$, signifies that $A$ is in a constant Ratio to $\frac{B C}{D}$; that is (if $a, b, c, d$ be other Values of these Quantities) A : $\frac{\mathrm{BC}}{\mathrm{D}}:: a:{ }^{b c}$; and thus every general Proportion is to be understood."

Florian Cajori.

I Gordon Street, Gordon Square, 'London, W.C.

\section{SCIENCE AND MUNITIONS OF WAR.} WE give in another column the names of the is assisting the Admiralty in the co-ordination and encouragement of scientific effort in relation to the requirements of the Naval Service. The Central Committee and the Panel of Consultants form as strong a body of expert opinion as it would be possible to bring together; and their judgment upon scientific matters submitted to them may be accepted with confidence. Suggestions and inventions sent to the Admiralty will, if they relate to naval matters, first be considered by officials of the existing staff, and any promising ideas or devices will be passed on to the Central Committee, consisting of Lord Fisher, Sir J. J. Thomson, Sir C. A. Parsons, and Dr. G. T. Beilby. This committee, when necessary or desirable, will refer particular points to members of the panel of consultants, which includes leading workers in chemistry, physics, metallurgy, and various branches of engineering science. The president of the Royal Society is one of the consultants, and with one exception all the other advisers are fellows of the society, which is thus giving of its best to the service of the country.

Since the early days of the war the Royal Society has been in close touch with the naval and military authorities with regard to scientific problems presenting themselves in the course of the operations. In the autumn the Council set up an organisation which has been expanded in various directions to meet the continually increasing requirements of the Government for scientific assistance. It consisted essentially of a general controlling committee, which was at first appointed ad hoc, but is now the Council itself; and sectional committees, each of which represents one of the several branches of science concerned, namely chemistry, engineering, physics, and physiology. Each committee has been placed by the council in charge of a chairman of acknowledged eminence. The Governmental de- partments concerned have nominated special representatives who sit as members of the sectional committees, and through them and the committees' own officers confidential relations have been established with those departments. The committees also are in touch with the scientific institutions and manufacturing centres throughout the country. These committees as working bodies are necessarily limited in size, having regard to the very confidential nature of the subjects submitted to them; but they avail themselves largely, as circumstances require, of the services of investigators outside their own membership.

The value of the work thus accomplished was publicly recognised by the Prime Minister lately in his remarks in the House of Commons. But though the Government has acknowledged that scientific men have rendered valuable assistance in connection with problems arising out of the war, no definite scheme seems yet to exist for the organisation of our scientific forces into a composite body. The Chemical Society, as we announced on July 8 , has taken steps of its own accord to form a consultative council upon which kindred societies such as the Institute of Chemistry, the Society of Chemical Industry, the Society of Public Analysts, the Pharmaceutical Society, and the Institution of Mining and Metallurgy will be represented. Scientific and industrial knowledge and interests are thus intimately associated, as they should be, but the relation of this group of chemical societies to the Physical Society, which has also formed a committee to consider suggestions and inventions, or to the war con1mittees of the Royal Society, does not appear to have been settled. Unless there is close co-operation between the committees of the various scientific societies it is difficult to see how overlapping will be prevented or how combined expert knowledge can be concentrated upon physical, chemical, and engineering problems requiring early and practical solution.

In addition to appointing committees to consider suggestions or inventions, the Royal, Chemical, and Physical Societies have taken steps to obtain registers of their fellows classified according to special knowledge and to scientific services which the fellows are willing, as well as specially qualified, to perform. The idea in each case is to secure co-operation among the fellows of the particular societies, and to examine by means of committees any promising suggestions relating to munitions of war or kindred subjects. No one knows precisely what will be done with the registers when they have been completed. Each society seems to be compiling its list independently and without any clear view of the use which will be made of the experts' services which will become available by the response to its circular. No scheme has yet been put forward by which definite national duties will be assigned to the hundreds of scientific men who are enrolling themselves on the registers of their respective societies.

The case is different with men who are NO. 2386 , VOL. 95] 
capable of taking their places in workshops. A register of the names and addresses of all persons who are willing to devote either the whole or some definite part of their time to industrial service of the kind indicated is being made at many engineering laboratories, so that no one with any mechanical aptitude need now lament absence of opportunity of employment in national work.

In a number of engineering laboratories of universities and technical colleges in different parts of the country, short courses are now being conducted by means of which, for a nominal fee, preliminary training can be obtained which will enable suitable persons to be recommended by the Local Munitions Committees for employment in the manufacture of munitions of war. Practical experience of employers has shown that comparatively unskilled assistance may materially increase the output of munitions in a district. Of course, persons who have already had some experience in engineering workshops can render more effective service than those who lack such experience; but there is much work to be done on machines which are so arranged that unskilled men-or womencan use them after very little preliminary training. The classes arranged in engineering laboratories will provide the necessary instruction to enable these persons to perform useful national work.

The laboratories of our universities, university colleges, and technical institutions are at the disposal of the Government, and in many of them men are devoting twelve hours a day to work in connection with the supply of munitions of war. A few days ago the members of the Royal Institution decided to offer the resources of their laboratories and of the Davy Faraday Research Laboratory to the Government for the prosecution of any particular research by officers of the Admiralty, War Office, or Ministry of Munitions; and the managers invited communication from these departments "in case there is any field of research in relation to or connected with chemical and physical science, or either of them, to which the professors, assistants, and staff of the Royal Institution or of the laboratory can usefully direct their attention with the view of giving assistance to his Majesty's Government in the conduct of the war."

We notice that this resolution was sent to the First Lord of the Admiralty, the Minister of War, the Minister of Munitions, and the chairman of the Inventions Board of the Admiralty, but we can scarcely suppose that each of these officers of State will act independently in making whatever use is possible of the offer. Mr. Lloyd George has announced in the House of Commons that he has made arrangements with the Secretary of State for War to take over the invention work relating to the munitions of war for the supply of which his department is responsible. He has also arranged with the First Lord of the Admiralty to take over the work relating to new expedients and inventions for purely Army purposes which are at present in charge of that department.

This action is in the direction of the establishment of the proposed central committee or bureau NO. 2386 , VOL. 95] to direct scientific and inventive energy into channels of effective work. In his recent address to the British Science Guild, Sir William Ramsay described Lord Sydenham's scheme for the constitution by the Royal Society of a general advisory committee to which all Departments of State would be directed to apply for assistance in problems requiring scientific treatment and investigation. The Royal Society is already in close association with the Government departments, and has instituted helpful work on many problems relating to the war, but there seems to be a need for common action between it and other scientific societies, both as regards the preparation of a joint register and the co-ordination of consultative committees. When such an organisation has been established, it should not be in separate connection with the Admiralty, War Office, Ministry of Munitions, and Board of Trade, but with a bureau to which scientific suggestions or inventions would be addressed, with the sure and certain knowledge that they would be submitted to expert trial and judgment. It is not yet clear whether Lord Fisher's Board is to be this central body or whether further committees are to be established by other Government departments concerned with scientific problems of the war and munitions. Good organisation demands concentration of effort upon common problems; and that end will not be reached by separate departments and separate scientific societies appointing their own committees and panels of consultants for independent work and advice. Co-ordination might be attained by the constitution of a grand committee on which each department and each scientific society concerning itself with national work would be represented, or a sort of official exchange might be established to which all suggestions or needs would be communicated, either to be dealt with by a small scientific staff attached to it or distributed to expert advisers for judgment. Only by linking up the various departments with one another and with scientific societies somewhat in this fashion can overlapping be avoided and the fullest advantage be secured most expeditiously from the services which men of science are prepared to place at the country's disposal.

Most people assume that these services will be voluntary; and a correspondent directs our attention to the fact that in the forms circulated by the Physical Society in connection with the proposed "War Register," it is stated that: "It is to be understood that all service. would be voluntary, and unpaid, being given for the good of the country during this period of emergency." $\mathrm{He}$ adds : "I should like to inquire how it comes about that the Physical Society is not in a position to offer remuneration for work of the character specified in the circular on a scale at least bearing a reasonable proportion to the wages paid by the Government for the performance of less responsible labour. Is it really for the good of the country that this work should be unpaid?"

Government departments and statesmen find their requests for expert advice and guidance re- 
sponded to so willingly by scientific men and societies that they overlook the necessity of making any recompense for work done. In the medical services every qualified practitioner receives rank and reasonable pay, while consultants are given generous retaining fees. In legal circles also no advice is expected without a retainer is attached to it; and in this connection we are interested in the announcement that "according to a statement made in the House of Commons Sir John Simon, as Attorney-General, drew $18,000 l$. as his remuneration for the past year." It should be unnecessary to urge that the laws of nature are of as much importance as the laws of the land, and that as in the present crisis men of science can be of greater service to the nation than lawyers or politicians, they should receive at least sufficient reward for it to enable them to put aside their daily work in order to take up national duties. There will be no lack of volunteer workers among scientific men, but the State should understand that its responsibility for payment on account of expert opinion is at least as great in the case of science as it is in law, medicine, and engineering.

\section{THE EVOLUTION OF THE GONIOMETER.}

THE goniometer-as the instrument used for 1 the measurement of the interfacial angles of crystals is called-has gradually developed from a simple and crude piece of apparatus to a refined and somewhat complex optical instrument, and the measurements made with it have become increasingly more accurate as the form improved, while on the other hand the methods of investigating the morphological characters of crystals have on the whole become simpler. Nicolaus Steno, who (in 1669) was the first to study the angles between the plane surfaces of crystals, laboriously determined them by slicing the crystals perpendicular to the edges bounding the faces in question, and outlining the sections on paper. The first instrument used for the purpose of measuring the interfacial angles is that known as the contact-goniometer, and was devised by Carangeot in 1783 ; it is used to this day for measuring large rough crystals. This type consists essentially of two arms, one movable with respect to the other, which are laid on the faces in question at right angles to their common edge; the position on a graduated scale of the end of the movable arm beyond the pivot gives the angle required. A cheap form of this type made in cardboard or celluloid was designed by S. L. Penfield in rgoo. Accuracy to single degrees of arc is the utmost that can under the most favourable conditions be expected of the contact-goniometer.

To the ingenuity of W. H. Wollaston, in 1809 , is due the reflective form of goniometer. In this type the common edge of the pair of faces under measurement is set in line with the axis of a rotatable graduated circle, and the position of the circle is read when some distant signal is reflected by the particular face in a predetermined NO. 2386 , VOL. 95] direction; the circle is rotated, and the reading taken corresponding to the second face. The difference betwen the pair of readings gives the interfacial angle required. In the original form the graduated circle was vertical, and no means existed for fixing accurately the direction of reference. In a goniometer described shortly afterwards, in I810, by E. L. Malus, a telescope of low power was used for receiving the reflections, and assuring, therefore, the constancy of the direction of reference, and in $1839 \mathrm{~J}$. Babinet designed an instrument with a horizontal circle. E. Mitscherlich introduced many improvements and accessories in I843; he added a collimator in place of a distant signal, and his screw arrangements for centring and adjusting the crystal are in principle the same as those generally used now. The horizontal-circle form of goniometer is extensively used at the present day, and the optical features and accessories have been brought to a high standard of perfection by the well-known firm of R. Fuess, of Berlin, who have devoted considerable attention to crystallographical instruments. Spider-lines were first used in the collimator, and afterwards the ordinary spectroscope-slit, but neither are satisfactory for goniometer work owing to the diffusion of the image on reflection at the tiny faces such as often occur on crystals. The difficulty was investigated by C. F. M. Websky, and in 1878 he described a slit, the jaws of which consisted of coplanar circular discs in contact, or nearly so, at the middle. This slit allows plenty of light to pass at the top and bottom, and the constriction at the centre admits of refined readings. In its original form, or slightly modified, this slit is universally used in modern goniometers. For the purpose of viewing the crystal while in position and determining what face gives a particular reflection, the telescope is usually supplied with a lens which is applied in front of either the objective or the eyepiece for converting it into a microscope of low power. In a well-made instrument, if the crystal reflections admit, readings may be made to 30 minutes of arc.

Various modifications of this type have from time to time been devised. In $1903 \mathrm{H}$. A. Miers used an inverted form, that is one in which the crystal is suspended below the graduated circle, for making observations on crystals growing in their mother liquor. He also designed a stage goniometer for the measurement of the optic axial angle of small crystal flakes under the microscope. More recently, in I9I I, Dr. A. Hutchinson designed a convenient form of inverted goniometer for the study and measurement of tiny crystals or crystal fragments. In the universal goniometer (Fig. I), as he terms it, the telescope $\mathrm{A}$ and collimator $\mathrm{C}$ are placed at some convenient angle to one another, and a microscope $B$ is so arranged that its axis bisects the angle between them. The instrument may be used in the ordinary way as a goniometer, as an axial-angle apparatus (a fitting carrying nicol and condensing lens being placed for the purpose opposite the microscope), as a total-reflectometer of the Kohl- 